\title{
DENSIDADE BÁSICA DO COLMO E SUA CORRELAÇÃO COM OS VALORES DE BRIX E POL EM CANA-DE-AÇÜCAR (1)
}

\author{
ANISIO AZZINI $(2,7)$, MARCO ANTONIO TEIXEIRA ZULLO $\left({ }^{3,7}\right)$, \\ MARIA CARLA QUEIROZ DE ARRUDA $\left({ }^{2,4}\right)$, CÂNDIDO RICARDO BASTOS $\left({ }^{5}\right)$ \\ e ANTÔNIO ALBERTO COSTA (6)
}

\begin{abstract}
RESUMO
Neste estudo procurou-se estabelecer as correlaçōes entre a densidade básica do colmo e os valores de Brix e Pol em diversas variedades e "seedlings" de cana-de-açucar, visando ao estabelecimento de um método expedito e semiquantitativo de análise. Os resultados obtidos mostraram correlaçōes significativas ( $p>99 \%$ ) entre a densidade básica do colmo e os valores obtidos para Brix e Pol, principalmente para a região mediana do colmo. Desse modo, a densidade básica do colmo pode ser utilizada como um método expedito de análise para avaliar a concentração de sacarose em canade-açúcar.
\end{abstract}

Termos de indexação: cana-de-açúcar; Saccharum spp.; sacarose; concentraçāo; densidade básica, Brix e Pol.

(1) Recebido para publicação em 17 de setembio de 1985.

(2) Seção de Plantas Fibrosas, Instituto Agronômico (IAC), Caixa Postal 28, 13001 Campinas (SP).

(3) Seção de Fitoquímica, Instituto Agronômico.

(4) Química Tecnб́loga. Bolsista da FAPESP.

(5) Divisão de Plantas Industriais, IAC.

(6) Seção de Cana-de-Açúcar, IAC.

(7) Com bolsa de suplementação do CNPq. 


\section{INTRODUÇĀO}

A análise tecnológica convencional de cana-de-açúcar visando à determinação dos teores de sacarose e açúcares redutores (glicose e frutose) é trabaIhosa e complexa, exigindo a utilização de aparelhos sofisticados e mão-de-obra especializada. Estudos conduzidos por AZZINI et alii (1980), com a variedade NA56-79, revelaram alto nivel de correlação $(r=0,99)$ entre a densidade básica do colmo e seu teor em açúcares no caldo, determinado como graus Brix. Esse resultado evidenciou a possibilidade de avaliar a concentração de sacarose na cana através de uma característica física do colmo - a densidade básica.

No presente estudo, onde se trabalhou com diversos materiais genéticos, procurou-se estabelecer a relação entre a densidade básica do colmo e sua concentração em sacarose, obtida a partir da análise convencional. O objetivo deste estudo foi estabelecer um procedimento simples de análise a ser utilizado, principalmente, na seleção inicial de materiais genéticos em programas de melhoramento de cana-de-açúcar.

\section{MATERIAL E MÉTODOS}

Neste estudo foram utilizados diversos materiais genéticos de cana constituídos de nove variedades, e sessenta "seedlings", representados por colmos com dez e doze meses de idade respectivamente, num total de 105 colmos provenientes de experimentos conduzidos pela Seção de Cana-de-Açúcar. As variedades foram representadas por cinco colmos e os "seedlings" por apenas um, e de cada colmo foram retirados dois internódios, obtidos nas suas regiōes basal ( $2^{\circ}$ internódio) e mediana (do $7^{\circ}$ ao $\left.9^{\circ}\right)$. Em seguida, os internódios foram divididos ao meio, sendo metade utilizada para a determinação da densidade básica $\mathrm{e}$, metade, processada convencionalmente conforme metodologia empregada pela Seção de Fitoquimica, incluindo as modificações propostas por ZULLO \& RAMOS (1984) para o cálculo dos resultados.

A densidade básica $(\mathrm{Db})$ toi determinada pela relação entre o peso da amostra seca em estufa a $105 \pm 3^{\circ} \mathrm{C}$ e seu volume saturado, obtido pelo deslocamento da água em proveta graduada, conforme procedimento utilizado por AZZINI et alii (1980). Conhecendo-se a densidade básica e as porcentagens de Brix do caldo extraído $(\mathrm{B} \% \mathrm{CE})$, do Pol do caldo extraído (P\%CE), de Brix da cana $(\mathrm{B} \% \mathrm{C})$ e de Pol da cana $(\mathrm{P} \% \mathrm{C})$, estabeleceram-se as correlações entre esses valores e a densidade básica para cada amostra.

\section{RESULTADOS E DISCUSSĀO}

Os resultados médios obtidos para a densidade básica, Brix e Pol em função das variedades e "seedlings" de cana-de-açúcar e das posiçōes de amos- 


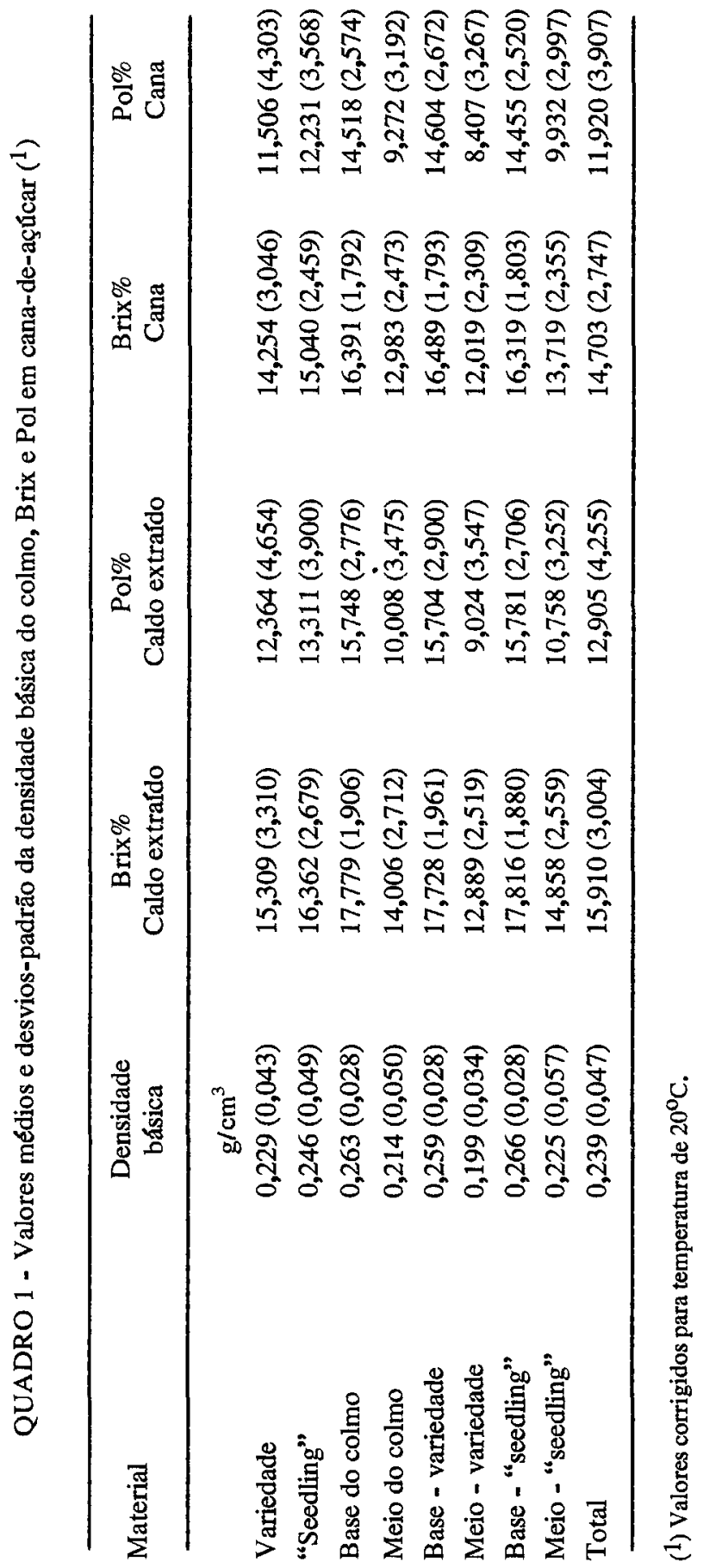




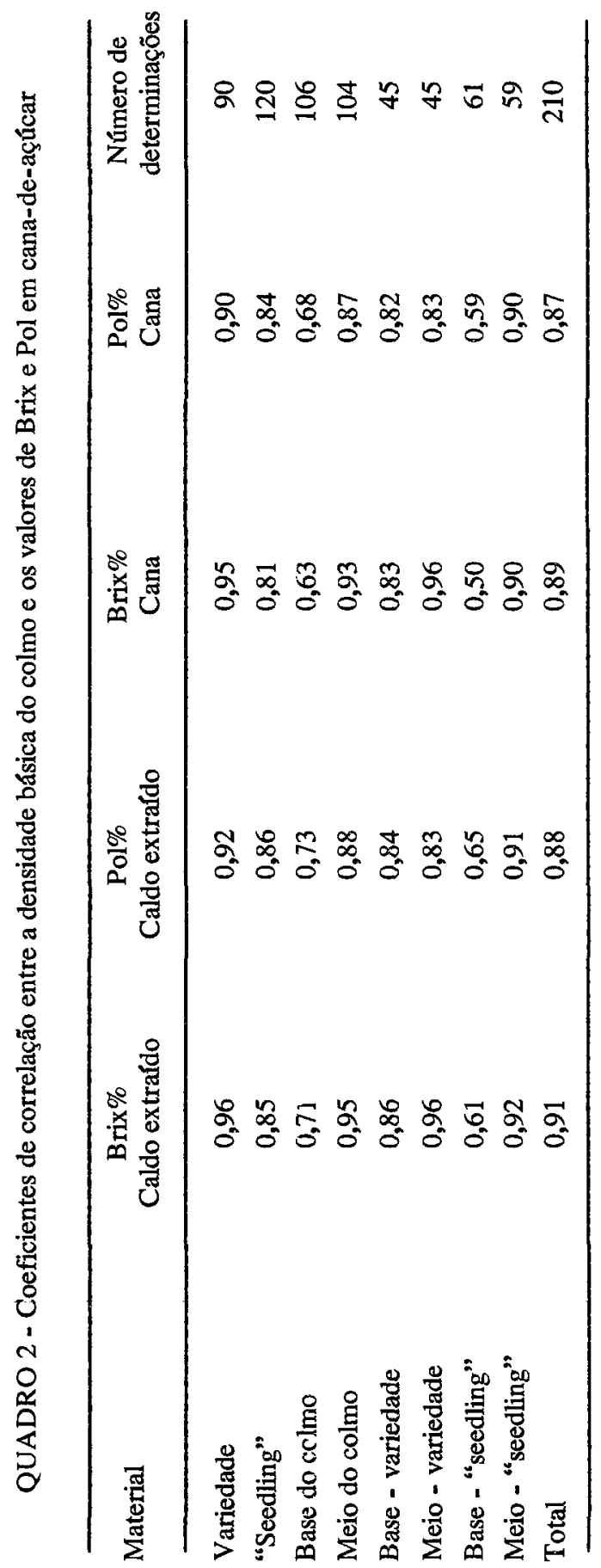


tragem no colmo (base e meio) encontram-se no quadro 1. A apresentação em separado dos materiais genéticos não teve a finalidade de fazer comparações entre variedades e "seedlings", mas, sim, de quantificar a variabilidade nas suas caracteristicas tecnológicas. Esses dados mostram que as regiōes basais dos colmos apresentaram valores mais elevados para a densidade básica, Brix e Pol, evidenciando maior concentração de açúcares nessas regiões. Esses resultados, relativamente a densidade básica e Brix, coincidem com aqueles obtidos por AZZINI et alii (1980) com a variedade NA56-79.

As correlações existentes entre a densidade básica do colmo e os valores de Brix e Pol (Quadro 2) estão associadas à concentração de sacarose, que apresenta um elevado peso específico $\left(1,58 \mathrm{~g} / \mathrm{cm}^{3}\right)$ em comparação aos demais componentes do caldo (água, glicose e frutose). Esse fato, aliado à homogeneidade anatômica do colmo de cana, principalmente nas regiōes basal e mediana, evidencia que maior concentração de sacarose resulta em maior densidade básica do colmo.

As correlações mais significativas $(p>0,99)$ foram obtidas na região mediana dos colmos, cujos valores de " $r$ " variaram de 0,87 a 0,95 . Dessas correlaçōes, a de maior interesse é aquela que relaciona a densidade básica do colmo e a concentração de sacarose, determinada como Pol da cana. Pelos resultados obtidos neste estudo, a densidade básica do internódio proveniente da região mediana do colmo pode ser utilizada para avaliar indiretamente a concentração de sacarose na cana através da seguinte equação de regressão:

$$
P \% C=-6,950+75,011 \mathrm{Db}
$$

Considerando as condiçōes específicas em que o presente estudo foi conduzido, pode-se concluir que o procedimento empregado na determinação da densidade básica do colmo representa um método expedito e semiquantitativo de análise, podendo ser utilizado pelo melhorista na seleção inicial de materiais genéticos em programas de melhoramento de cana-de-açúcar.

\section{SUMMARY}

\section{CORRELATION BETWEEN BRIX AND POL VALUES OF SUGARCANE AND CULM BASIC DENSITY}

The correlation between the refractometric (Brix) and polarimetric (Pol) determinations and the culm basic density was determined. The objective was to establish a fast and semiquantitative method for sugarcane analysis, regarding sucrose determination in the culm. The results showed a significant correlation $(p>0.99)$ between the basic density and each of the values of Brix and Pol, mainly for the median portion of the culm. It was concluded that the culm basic density can be utilized as a speedy method to estimate the sucrose concentration of sugarcane culms.

Index terms: sugarcane, Saccharum spp., sucrose concentration, basic density, Brix and Pol. 


\section{AGRADECIMENTOS}

Os autores agradecem aos Pesquisadores Científicos Maria Tereza Baraldi Ramos e João Paulo Feijão Teixeira as sugestões na execução do presente estudo.

\section{REFERÊNCIAS BIBLIOGRÁFICAS}

AZZINI, A.; TEIXEIRA, J.P.F.; MORAES, R.M. \& CAMARGO, A.J.F.P. Correlação entre o teor de sólidos soláveis do caldo e a densidade básica do colmo de cana. Bragantia, Campinas, 39:181-183, 1980.

ZULLO, M.A.T. \& RAMOS, M.T.B. Cáculo de resultados em análises tecnológicas de cana-de-açúcar pelo método da prensa. Pesquisa Agropecuária Brasileira, Brasilia, 19(4):495-498, 1984. 